Published in final edited form as:

J Am Chem Soc. 2016 April 13; 138(14): 4900-4907. doi:10.1021/jacs.6b01285.

\title{
The N-B Interaction through a Water Bridge: Understanding the Chemoselectivity of a Fluorescent Protein Based Probe for Peroxynitrite
}

\author{
Zhi-jie Chen $^{\dagger}$, Ziqi Tian ${ }^{\dagger}$, Karen Kallio ${ }^{\ddagger}$, April L Oleson ${ }^{\ddagger}$, Ao $\mathrm{Ji}^{\dagger}$, Dan Borchardt ${ }^{\dagger}$, De-en \\ Jiang ${ }^{\dagger}$, S. James Remington ${ }^{\ddagger},{ }^{*}$, and Hui-wang $\mathrm{Ai}^{\dagger},{ }^{*}$ \\ †Department of Chemistry, University of California at Riverside, 501 Big Springs Road, Riverside, \\ CA 92521, United States of America \\ ¥Department of Physics and Institute of Molecular Biology, University of Oregon, Eugene, OR \\ 97403, United States of America
}

\begin{abstract}
Boronic acid and esters have been extensively utilized for molecular recognition and chemical sensing. We recently reported a genetically encoded peroxynitrite $\left(\mathrm{ONOO}^{-}\right)$-specific fluorescent sensor, pnGFP, based on the incorporation of a boronic acid moiety into a circularly permuted green fluorescent protein (cpGFP) followed by directed protein evolution. Different from typical arylboronic acids and esters, the chromophore of pnGFP is unreactive to millimolar concentrations of hydrogen peroxide $\left(\mathrm{H}_{2} \mathrm{O}_{2}\right)$. The focus of this study is to explore the mechanism for the observed unusual chemoselectivity of pnGFP toward peroxynitrite over hydrogen peroxide by using site-directed mutagenesis, X-ray crystallography, ${ }^{11} \mathrm{~B}$ NMR, and computational analysis. Our data collectively support that a His residue on the protein scaffold polarizes a water molecule to induce the formation of an $\mathrm{sp}^{3}$-hybridized boron in the chromophore, thereby tuning the reactivity of pnGFP with various reactive oxygen and nitrogen species (ROS/RNS). Our study demonstrates the first example of tunable boron chemistry in a folded nonnative protein, which offers wide implications in designing selective chemical probes.
\end{abstract}

\section{Graphical abstract}

\footnotetext{
*Corresponding Authors: huiwang.ai@ucr.edu, remington@molbio.uoregon.edu. ASSOCIATED CONTENT Supporting Information

The sequences of oligonucleotides used in this study, crystallographic data, refinement and atomic model statistics, optimization of the expression of $p$ BoF-containing proteins, ${ }^{11} \mathrm{~B}$ NMR spectra for pnGFP, and ${ }^{11} \mathrm{~B}$ NMR titration of phenylboronic acid with imidazole. The Supporting Information is available free of charge on the ACS Publications website.

The authors declare no competing financial interest. The structural coordinates and diffraction data of pnGFP1.5-Y.Cro have been deposited in the Protein Data Bank (PDB) under accession code 5F9G.
} 


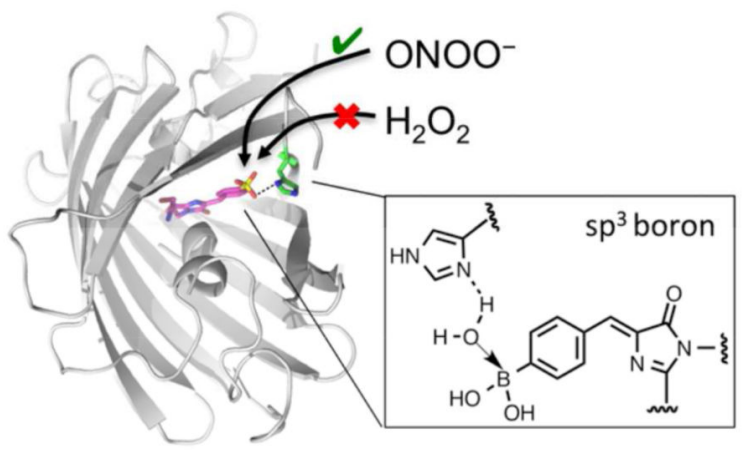

\section{INTRODUCTION}

Boronic acids and esters are widely used chemical moieties for assembling organic molecules, ${ }^{1-2}$ inhibiting serine proteases,${ }^{3-4}$ and sensing vicinal diol-containing molecules (e.g. saccharides, nucleosides, and catecholamines) based on reversible covalent associations. ${ }^{5-8}$ Recently, ortho- ketone or aldehyde substituted arylboronic acids have been shown to undergo rapid conjugation with hydrazines or alkoxyamines at neutral $\mathrm{pH}$, which reaction has been utilized for biolabeling. Moreover, arylboronates have been utilized to sense reactive oxygen and nitrogen species (ROS/RNS), such as hydrogen peroxide $\left(\mathrm{H}_{2} \mathrm{O}_{2}\right)$ and peroxynitrite $\left(\mathrm{ONOO}^{-}\right) \cdot{ }^{9-10}$ In particular, peroxynitrite, a highly reactive oxidative and nitrosative species with a very short half-life $(<10 \mathrm{~ms})$ in biological systems, plays important roles in cell signaling, stress response, and pathogenesis. ${ }^{11}$ Peroxynitrite can mediate protein nitration to modulate enzymatic activity and protein stability, ${ }^{12-14}$ increase immunogenicity of modified proteins, ${ }^{15}$ induce protein-protein interaction by mimicking phosphotyrosine,${ }^{16}$ and cross-talk with tyrosine kinases and phosphatases by altering their substrate structures. ${ }^{13,17}$ As a strong oxidant and an excellent nucleophile, peroxynitrite and its secondary metabolites, such as hydroxyl radical $(\bullet \mathrm{OH})$, carbonate radical $\left(\mathrm{CO}_{3}{ }^{-}\right)$, and nitric dioxide radical $\left(\bullet \mathrm{NO}_{2}\right)$ can also induce DNA damage, lipid peroxidation, and protein oxidation and nitration, thereby leading to deregulated signal transduction, impaired physiological function, and cell death. ${ }^{18}$ Moreover, peroxynitrite plays protective roles against invading pathogens in the immune system. ${ }^{19}$

There is a high demand for reliable and sensitive analytical methods to elucidate this signal/ stress dichotomy of peroxynitrite, among other roles. ${ }^{20}$ Accordingly, a growing list of fluorescent probes for peroxynitrite has recently emerged, ${ }^{10,21-34}$ with some of which proven promising for use in biological contexts. ${ }^{23,34-36}$ In particular, arylboronates have been shown to quickly react with peroxynitrite, and the reaction has been utilized to develop a number of fluorescent sensors for peroxynitrite. ${ }^{33,37}$ Although their reactivity toward peroxynitrite is nearly a million times faster than their reaction with hydrogen peroxide, these arylboronate fluorescent probes nevertheless also respond to hydrogen peroxide. ${ }^{38}$ Considering that hydrogen peroxide is normally generated at markedly higher concentrations and with a much longer half-life in vivo, Chang et al. have utilized arylboronates for detection of hydrogen peroxide in living cells and animals. ${ }^{9,39-40}$ 
Our laboratory recently reported pnGFP, the first and the only existing genetically encoded fluorescent probe for peroxynitrite. ${ }^{21}$ pnGFP was developed by site-specific incorporation of $p$-boronophenylalanine $(p \mathrm{BoF})$, in place of Tyr, at the chromophore of a circularly permuted green fluorescent protein (cpGFP). Engineering of the cpGFP scaffold containing the nonnative chromophore led to a hybrid protein, whose fluorescence could be selectively activated by peroxynitrite, but not by hydrogen peroxide at low millimolar concentrations. Mass spectrometry analysis suggested that the boronic acid-derived chromophore was mainly oxidized into a phenolate form by peroxynitrite, accompanied by a drastic fluorescence enhancement. ${ }^{21}$ Like small molecule-based arylboronate probes, most parental mutants of pnGFP, including cpGFP2-Tyr66 $p$ BoF, responded to both peroxynitrite and hydrogen peroxide. We previously attributed the mysterious chemoselectivity of pnGFP to interactions between the boronic acid-derived chromophore and hydroxyl groups of Ser or Thr residues on the protein scaffold. We now have re-investigated this problem using sitedirected mutagenesis, X-ray crystallography, ${ }^{11} \mathrm{~B}$ NMR, and computational analysis. Our major finding is that an unexpected $\mathrm{N}-\mathrm{B}$ interaction through a polarized water molecule converts the boron atom of the pnGFP chromophore to be $\mathrm{sp}^{3}$-hybridized, leading to the structural basis for the unprecedented chemoselectivity of pnGFP. With this study, we present a unique example of the N-B interaction in an engineered protein modulating the chemoreactivity of an aryl boronate moiety. Future studies focusing on development of aryl boronate-based sensors or tuning of chemical reactions using protein cages should also greatly benefit from the mechanistic details revealed in this study.

\section{EXPERIMENTAL SECTION}

\section{General Method and Materials}

The amino acid, $p \mathrm{BoF}$, was purchased from Synthonix (Wake Forest, NC). Synthetic DNA oligonucleotides were purchased from Integrated DNA Technologies (San Diego, CA). Restriction endonucleases were purchased from Thermo Fisher Scientific (Waltham, MA). PCR and restriction digestion products were purified by gel electrophoresis and extracted using the Syd Labs Gel Extraction kit (Malden, MA). Plasmid DNA was purified using the Syd Labs Mini-prep kit (Malden, MA). DNA sequence analysis was performed by Retrogen (San Diego, CA). ${ }^{11}$ B NMR spectroscopy was conducted on a Bruker Avance 600 at the UCR Analytical Chemistry Instrumentation NMR Facility.

\section{Site-Directed Mutagenesis}

An overlap extension PCR strategy was used to create most pnGFP mutants. The sequences of all used oligonucleotides are shown in Supporting Information Table S1. Briefly, two complementary mutagenic oligonucleotides were paired with either N- (pnGFP-F) or C(pnGFP-R) terminal flanking primer to amplify fragments of pnGFP in two separate PCR reactions. Products were purified by gel electrophoresis and extraction, and mixed together as the templates in a subsequent PCR reaction with both $\mathrm{N}$ - and C- terminal flanking primers to generate full-length fragments of pnGFP mutants. To create a pnGFP-His9Thr mutant, a mutation-containing primer, pnGFP-H9T-F, was paired with pnGFP-R to directly amplify pnGFP, because His9 is close to the N-terminus. The final PCR products were then digested with Xho I and Hind III, and ligated into a predigested compatible pBAD-pnGFP plasmid. 
DNA sequencing with oligonucleotides pBAD-F or pBAD-R confirmed the sequences of all pnGFP mutants.

\section{Protein Expression and Purification}

To express pnGFP in a large quantity, pBAD-pnGFP was used to cotransform C321. $\triangle \mathrm{A}$.exp E. coli cells along with $\mathrm{pEvol}-p \mathrm{BoF}$. A single colony was chosen to grow at $37^{\circ} \mathrm{C}$ in $20 \mathrm{~mL}$ LB medium supplemented with $100 \mu \mathrm{g} / \mathrm{mL}$ ampicillin and $50 \mu \mathrm{g} / \mathrm{mL}$ chloramphenicol. Saturated overnight cultures of cells were then diluted by 100 -fold into $2 \mathrm{~L}$ Terrific Broth (TB) and grown to $\mathrm{OD}_{600}=0.6$ when L-arabinose (final conc. $0.2 \%$ ) and $\mathrm{pBoF}$ (final conc. $1 \mathrm{mM}$ ) were added to induce the expression of pnGFP. Growth continued with vigorous shaking at $37^{\circ} \mathrm{C}$ for 24 hours, and next at room temperature for another 72 hours with additional $0.2 \%$ L-arabinose added every other day. Cells were harvested and lysed by sonication. His $_{6}$-tagged proteins were purified by Ni-NTA affinity chromatography according to the manufacture's instructions (Thermo Fisher Scientific, Waltham, MA), dialyzed into Tris-HCl buffer ( $30 \mathrm{mM}$, pH 7.4) using Thermo Scientific Snakeskin dialysis tubing (7,000 Da cutoff), and concentrated using Amicon Ultra Centrifugal Filter Units (3,000 Da cutoff). Bradford Assays were performed to determined protein concentrations by comparison to a set of bovine serum albumin (BSA) standards. In our study, we also utilized a further enhanced pnGFP variant, pnGFP1.5, of which the engineering and detailed characterization will be described elsewhere. By following the same procedure for the preparation of pnGFP, we prepared $p$ BoF-containing pnGFP1.5 in a large quantity. The procedures to express, purify, and quantify other $p \mathrm{BoF}$-containing pnGFP mutants were identical to the procedures detailed above, except that $50 \mathrm{~mL}$ TB was used for each mutant. Moreover, we utilized a pnGFP1.5 variant, pnGFP1.5-Y.Cro, which contains a Tyr-derived chromophore. The gene fragment was cloned into a pCDF-1b vector (Novagen, Madison, WI). We used the plasmid to transform BL21(DE3) E. coli cells, which were next selected against $50 \mu \mathrm{g} / \mathrm{mL}$ spectinomycin on LB agar plates. Saturated overnight culture from a single colony was then diluted 100-fold with fresh 2YT medium supplemented with 50 $\mu \mathrm{g} / \mathrm{mL}$ spectinomycin. Protein expression was induced at OD600 $=0.8$ with $1 \mathrm{mM}$ IPTG, followed by continuous growth at $37^{\circ} \mathrm{C}$ for 24 hours and at room temperature for another 24 hours. Cells were harvested. The pnGFP1.5-Y.Cro protein was purified with Ni-NTA affinity chromatography, dialyzed into a buffer containing $50 \mathrm{mM}$ HEPES (pH 7.5), $3 \mathrm{M} \mathrm{NaCl}$, and $1 \mathrm{mM} \beta$ mercaptoethanol, and concentrated to an absorbance of 52 at $280 \mathrm{~nm}$ for crystallization setup.

\section{Fluorescence Spectroscopic Characterization}

A monochromator-based Synergy Mx Microplate Reader (BioTek, Winooski, VT) was used for all fluorescence measurements. For single-point fluorescence measurements, excitation was set at $480 \mathrm{~nm}$ and emission was set at $510 \mathrm{~nm}$. A final protein concentration of $0.5 \mu \mathrm{M}$ was used in all assays. To perform time-lapse measurements, pnGFP or mutant proteins were diluted with an aqueous buffer containing $150 \mathrm{mM}$ Tris- $\mathrm{HCl}$ and $150 \mathrm{mM} \mathrm{NaCl}(\mathrm{pH}$ 7.4). The mixtures were next incubated with peroxynitrite $(100 \mu \mathrm{M})$ or hydrogen peroxide $(100 \mu \mathrm{M})$ in individual wells of 96 -well plates, and monitored for one hour at room temperature. The fold of fluorescence enhancement was defined as the ratio of the fluorescence intensity after treatment with peroxynitrite or hydrogen peroxide to the 
fluorescence intensity before any treatment. Data were given as mean \pm standard deviation based on three independent measurements.

\section{${ }^{11}$ B NMR Characterization}

pnGFP and pnGFP1.5 proteins were purified as described above, concentrated using Amicon Ultra Centrifugal Filter Units (3,000 Da cutoff), exchanged into $20 \mathrm{mM}$ phosphate (pH 7.4, $\left.\mathrm{D}_{2} \mathrm{O}(\mathrm{v}): \mathrm{H}_{2} \mathrm{O}(\mathrm{v})=1: 1\right)$ to final concentrations of 18.4 and $24.1 \mathrm{mg} / \mathrm{mL}$, respectively. ${ }^{11} \mathrm{~B}$ NMR spectra were acquired on a Bruker Avance 600 spectrometer operating at 192.507 MHz using a $5 \mathrm{~mm}$ Broadband Observe (BBO) probe. To minimize background signal from glass, samples were placed in quartz NMR tubes and an echo sequence employed (d1-90xtau-180x-tau-acquire, tau $=100 \mu$ s). Spectra were collected as the average of 320,000 scan, 16,384 complex data point FIDs with a $200 \mathrm{ppm}$ sweep width. To further remove background signal due to glass, back linear prediction within the topspin software was used $\left(\mathrm{ME} \_\mathrm{mod}=\mathrm{LPbc}, \mathrm{NCOEF}=8, \mathrm{LPBIN}=256\right.$, TDoff $\left.=64\right)$. Data were then processed in the normal manner with $100 \mathrm{~Hz}$ line broadening applied. Chemical shifts were referenced to external boron trifluoride etherate $\left(\mathrm{BF}_{3} \bullet \mathrm{Et}_{2} \mathrm{O}, \delta=0 \mathrm{ppm}\right)$. For comparison, we also recorded ${ }^{11} \mathrm{~B}$ NMR spectra for the following samples: phenylboronic acid $(20 \mathrm{mM})$ in the 20 $\mathrm{mM}$ phosphate buffer $\left(\mathrm{pH} 7.4, \mathrm{D}_{2} \mathrm{O}(\mathrm{v}): \mathrm{H}_{2} \mathrm{O}(\mathrm{v})=1: 1\right)$, phenylboronic acid $(20 \mathrm{mM})$ and imidazole $(1 \mathrm{M})$ in deuterated chloroform $\left(\mathrm{CDCl}_{3}\right)$, and phenylboronic acid $(20 \mathrm{mM})$ in $1 \mathrm{M}$ sodium hydroxide $(\mathrm{NaOH})$ aqueous solution $\left(\mathrm{D}_{2} \mathrm{O}(\mathrm{v}): \mathrm{H}_{2} \mathrm{O}(\mathrm{v})=1: 1\right)$.

\section{Protein Crystallization and Structure Determination}

Initial crystallization screens were carried out in Axygen 96-Well Sitting-Drop Crystallography Plate using the TTP Labtech Mosquito (TTP Labtech, Cambridge, MA). The screen conditions were PEG/Ion, PEG/Ion II, and the Index screen from Hampton Research (Aliso Viejo, CA). Large single crystals of pnGFP1.5-Y.Cro were obtained after optimization of condition 14 of PEG/Ion to $20 \% \mathrm{w} / \mathrm{v}$ polyethylene glycol 3350, $0.25 \mathrm{M}$ Potassium thiocyanate, and $1 \mathrm{M}$ Tris $\bullet \mathrm{HCl}(\mathrm{pH} 8)$. The cryoprotectant was $20 \%$ ethylene glycol in the crystal mother liquor. Diffraction data from two crystals were collected on Beamline 5.0.1 at the ALS (Advanced Light Source, Lawrence Berkeley Laboratory, Berkeley, CA). The structure was solved by molecular replacement from wild-type GFP (starting model PDB ID 1EMB), followed by model building and crystallographic refinement using the programs HKL2000, $\mathrm{CCP}_{4}$, EPMR, Coot, and Phenix. ${ }^{41-46}$

\section{Computational Analysis}

Density functional theory (DFT) calculations were performed with the Gaussian 09 software package. ${ }^{47} \mathrm{~A}$ fragment approach was used to examine the chemistry between pnGFP and peroxynitrite or hydrogen peroxide whereby the reactive residues of the protein were model with phenylboronic acid and imidazole (the Lewis base). Geometries were optimized at the DFT M06- $2 \times$ level with the $6-31+\mathrm{G}(\mathrm{d})$ basis set. ${ }^{48}$ Bonding strength between the boric species and the Lewis base was evaluated based on the binding energy, $\mathrm{E}_{\mathrm{b}}=\mathrm{E}_{\text {Complex }}+$ BSSE - $\mathrm{E}_{\text {Boric Species }}-\mathrm{E}_{\text {Lewis Base, }}$, where BSSE is the correction from the basis set superposition error. Natural bond orbital (NBO) analysis ${ }^{49}$ was employed to calculate atomic partial charges of the involved molecules. 


\section{RESULTS AND DISCUSSION}

\section{Reactions of pnGFP and Its Mutants with Peroxynitrite or Hydrogen Peroxide}

We originally considered that Thr5 and Thr253 of pnGFP (Figure 1) interact with the boron atom of the chromophore to confer the unusual chemoselectivity. ${ }^{21}$ We soon realized that the two residues are not major determining factors, because we engineered further improved mutants of pnGFP, which retain reasonable chemoselectivity with other amino acid residues at these two positions. We next compared pnGFP with an earlier mutant, cpGFP2Tyr66 $p \mathrm{BoF}$, which responded to both peroxynitrite and hydrogen peroxide. Sequence alignment (Figure 1) revealed a few mutations within pnGFP that attracted our attention. Based on the structural information on the wild-type GFP, we located residues His9, Thr64, and Ser66 of pnGFP, which are expected to be close to the boron atom of the chromophore. We hypothesized that His9, Thr64, or Ser66 might interact with the empty p orbital of boron, and that Thr64 or Ser66 might even form a boric ester bond with the $p$ BoF-derived chromophore. Additionally, we selected the first chromophore-forming residue (Thr173 in pnGFP) because of its potential to affect the electron distribution of the $p$ BoF-derived chromophore. Accordingly, we performed site-directed mutagenesis on pnGFP to independently mutate these residues back to their counterparts on cpGFP2-Tyr66 $p \mathrm{BoF}$, namely His9Thr, Thr64Phe, and Thr173Gly. Because cpGFP2-Tyr66 $p$ BoF and pnGFP share the same Ser66 residue, we mutated it to a nonpolar Ala, which is expected to disrupt the $\mathrm{H}$ bond network around the chromophore. To examine the reactivity and selectivity of these mutants, we prepared each of these $p \mathrm{BoF}$-containing proteins and characterized their responses to both hydrogen peroxide and peroxynitrite. When incubated with $100 \mu \mathrm{M}$ hydrogen peroxide for 1 hour, pnGFP-His9Thr showed an 11.5-fold fluorescence enhancement, whereas pnGFP and all other mutants were virtually non-responsive (Figures $2 \mathrm{~A}$ and 2B). All mutants except for pnGFP-Thr64Phe reacted robustly with $100 \mu \mathrm{M}$ peroxynitrite, as indicated from their significant fluorescence increases (Figure 2C).

The peroxynitrite-induced fluorescence enhancement of pnGFP-His9Thr was 2.6-fold higher than that of pnGFP, suggesting that pnGFP-His9Thr is more reactive toward both peroxynitrite and hydrogen peroxide, compared to pnGFP. pnGFP-Thr64Phe has very low fluorescence before and after treatment with either hydrogen peroxide or peroxynitrite, presumably because this mutation is not tolerable to the protein. We also derived the ratios of peroxynitrite-induced to hydrogen peroxide-induced fluorescence enhancements (Figure 2D), which show that pnGFP-His9Thr has the lowest selectivity in terms of its reaction toward peroxynitrite over hydrogen peroxide. The low selectivity of pnGFP-His9Thr and its high reactivity with hydrogen peroxide suggest that His9 plays a vital role in making pnGFP selective for peroxynitrite.

\section{Optimization of Conditions for the Biological Preparation of pnGFP}

To further our understanding of the unusual chemoselectivity of pnGFP, a large amount of the protein was needed. We tested various conditions (e.g. bacterial strains, inducer concentrations, temperature, induction time, and the culture medium) in order to identify an optimized condition for the preparation of pnGFP (Figure S1). By using a nutritionally rich $\mathrm{TB}$ medium and a genomically altered bacterial strain, $\mathrm{C} 321 . \Delta \mathrm{A} . \exp ,{ }^{50}$ we were able to 
purify $\sim 12 \mathrm{mg}$ of pnGFP from each liter of cell culture. C321. $\Delta$ A.exp contains a recoded $E$. coli genome, in which all 321 TAG stop codons was replaced with TAA and release factor 1 (RF1) - the only release factor recognizing the amber TAG codon, was deleted. ${ }^{50}$ Therefore, C321. AA.exp can be utilized to reassign TAG codons for highly efficient incorporation of nonnative amino acids. Using a similar condition, we also prepared pnGFP1.5, a mutant of pnGFP with improved folding and expression and still showing excellent selectivity toward peroxynitrite. The sequence of pnGFP1.5 is presented in Figure 1, and the details for its engineering, characterization, and application will be described elsewhere. The expression level of pnGFP1.5 was $\sim 50 \%$ higher than that of pnGFP under our optimized conditions.

\section{X-Ray Crystallography}

We used a wide range of conditions in the attempt to crystallize $p$ BoF-containing pnGFP1.5, but all experiments were unsuccessful. However, pnGFP1.5-Y.Cro, which is identical to pnGFP1.5 except for that Tyr replaces $p \mathrm{BoF}$ at residue 174 to form a wild-type GFP-like chromophore, crystallized readily in space group $\mathrm{P}_{3}{ }_{2}{ }_{1} 2$, with one monomer in the asymmetric unit. The atomic model was refined at $2.75 \AA$ resolution to a final R-factor of 0.203 (Table S2). As one would predict on the basis of the structures of other fluorescent proteins in the native and circularly permuted topologies, pnGFP1.5-Y.Cro forms a typical " $\beta$ can" structure shared by all GFP homologs. We compared the structure of pnGFP1.5Y.Cro with the crystal structure of a circular-permutated EGFP (PDB ID 3EVP). Both share $90 \%$ sequence identity and a $0.36 \AA$ rmsd (root mean square deviation) over 190 aligned atoms. The major differences are on the positions of several $\mathrm{N}$-terminal residues that are also close to the chromophores (Figures 3A). In 3EVP, the oxygen atom of the phenolate chromophore forms an $\mathrm{H}$-bond with a water molecule that in turn forms three $\mathrm{H}$-bonds with the side chains of Ser59 and Ser118 and the backbone carbonyl oxygen of Thr116 (Figure 3B). In pnGFP1.5-Y.Cro, the position of the water molecule is slightly shifted to form four H-bonds with the phenolate of the chromophore, the side chains of His9 and Ser66, and the backbone carbonyl oxygen of Thr64 (Figure 3C). Thr64 and Ser66 of pnGFP are structurally aligned with Thr116 and Ser118 in 3EVP, respectively. However, His9 of pnGFP is not structurally aligned with Ser59 in 3EVP, but rather occupies a similar position to that of Glu61 in 3EVP. The direct distance between the phenolate oxygen and the $\pi-\mathrm{N}$ of His9 is 4.0 $\AA$, whereas the distances between the phenolate oxygen and the oxygen of the bound water and between the oxygen of the bound water and the $\pi-\mathrm{N}$ of His 9 are $3.0 \AA$ and $2.8 \AA$, respectively.

\section{${ }^{11} B$ NMR Characterization Supporting an $s p^{3}$-Hybridized Boron in pnGFP}

Our site-directed mutagenesis study supports that His9 plays an important role in modulating the reactivity of the $p \mathrm{BoF}$-derived chromophore. Since His9 is spatially close to the boron atom, as indicated by the crystal structure of pnGFP1.5-Y.Cro, we postulate that the side chain of His9 may chemically interact with the $p \mathrm{BoF}$-derived chromophore in pnGFP or pnGFP1.5. When the boronic acid functional group replaces the phenolate oxygen in the pnGFP or pnGFP1.5 chromophore, the resulting unusual local environment may promote the formation of a dative bond between the empty boron $\mathrm{p}$ orbital and the $\pi-\mathrm{N}$ of His9 (Figure 4A), or between the empty boron p orbital and a bound water molecular polarized by His9 (Figure 4B). This will convert the boron atom from $\mathrm{sp}^{2}$ into $\mathrm{sp}^{3}$ 
hybridization. Therefore, we next utilized ${ }^{11} \mathrm{~B}$ NMR spectroscopy to investigate the bonding characteristics of the boron atom in the chromophore. We prepared pnGFP and pnGFP1.5 in large quantities, and recorded their ${ }^{11} \mathrm{~B}$ NMR spectra in a neutral phosphate buffer containing $50 \% \mathrm{D}_{2} \mathrm{O}(\mathrm{v} / \mathrm{v})$. A sharp single peak was observed for either pnGFP or pnGFP1.5 at $2.28 \mathrm{ppm}$ or $2.24 \mathrm{ppm}$ (Figure S2 and Figure 5), respectively, in reference to boron trifluoride etherate $\left(\mathrm{BF}_{3} \cdot \mathrm{Et}_{2} \mathrm{O}\right)$. In the meanwhile, we also recorded ${ }^{11} \mathrm{~B}$ NMR spectra for phenylboronic acid, and phenylboronic acid in $1 \mathrm{M}$ sodium hydroxide $(\mathrm{NaOH})$. The free phenylboronic acid, which is expected to be $\mathrm{sp}^{2}$-hybridized, showed a single ${ }^{11} \mathrm{~B}$ NMR peak at $28.17 \mathrm{ppm}$, whereas the phenyl boronate anion, which has an $\mathrm{sp}^{3}$-hybridized hydroxylated boron, produced a sharp peak at $2.56 \mathrm{ppm}$. We also performed the ${ }^{11} \mathrm{~B}$ NMR titration experiment with phenylboronic acid and imidazole (Figure S3). When the imidazole concentration increased from $0 \mathrm{mM}$ to $10 \mathrm{mM}$, the chemical shift reduced from $28.17 \mathrm{ppm}$ to $6.38 \mathrm{ppm}$. Fitting the data with a logistic model, we derived the chemical shift for the stable phenylboronic acid/imidazole complex to be $5.7 \pm 0.9 \mathrm{ppm}$. Based on our measurements and previous literature reports, ${ }^{51-54}$ the ${ }^{11} \mathrm{~B}$ NMR peaks for pnGFP and pnGFP1.5 were assigned to the fully hydrated $\mathrm{sp}^{3}$-hybridized boronate anion (Figure 4B). This assignment is well aligned with a previous study by Anslyn et al. stating that $\mathrm{sp}^{3}$ hybridized boronate with a direct N-B bond was $\sim 4$ ppm downfield from the fully hydrated species, and that in protic media, solvent insertion between $\mathrm{N}$ and $\mathrm{B}$ atoms was prevalent to form tetrahedral $\mathrm{sp}^{3}$-hybridized boronate anion. ${ }^{55}$ Moreover, our assignment corroborates the crystal structure of pnGFP1.5-Y.Cro, in which a His9-bound water molecular was observed (Figure 3C). Compared to pnGFP1.5-Y.Cro, only a minimal structural rearrangement around the chromophore is needed to form an $\mathrm{sp}^{3}$-hybridized hydrated boronate in pnGFP1.5.

\section{Computational Analysis}

To verify if the proposed formation of $\mathrm{sp}^{3}$ boron in Figure 4 is viable, we performed electronic-structure calculations based on density functional theory (DFT) of the molecular models from Figures 4A and 4B without explicitly including the whole protein or the solvent. His9 was simplified to imidazole, while the $p \mathrm{BoF}$-derived chromophore to the phenyl boronic acid. Geometry optimization showed that imidazole and phenylboronic acid spontaneously combine to form a dative bond of $1.632 \AA$ with a bonding energy $\left(\mathrm{E}_{\mathrm{b}}\right)$ of $-11.3 \mathrm{kcal} / \mathrm{mol}$ (Figure $6 \mathrm{~A}$ ), in consistent with previous studies on B-N bonds. ${ }^{56}$ In contrast, we found that water itself cannot spontaneously form a stable B-O dative bond with phenylboronic acid. However, in the presence of an imidazole group to polarize water, a stable B-O dative bond can form with a bond length of $1.661 \AA$ (Figure 6B). Although this bond is longer than the normal covalent $\mathrm{B}-\mathrm{O}$ bond in boronic acid $(1.372 \AA), \mathrm{E}_{\mathrm{b}}$ of this $\mathrm{B}-\mathrm{O}$ bond $(-10.9 \mathrm{kcal} / \mathrm{mol})$ is comparable to that of a $\mathrm{B}-\mathrm{N}$ dative bond. In this imidazole-waterboronic acid complex, the distance between nitrogen and boron is $3.557 \AA$, close to that between N in His9 and O in Tyr66 in the crystal structure of cpGFP (3.9 ̊ in Figure 3C). This implies that, in pnGFP, the His9-bound water molecule may readily combine with the $p$ BoF-derived chromophore to form an $\mathrm{sp}^{3}$-hybridized boronate without causing significant distortion to the protein backbone. 
All of our experiments combined with the computational verification support that the boron in pnGFP is in an $\mathrm{sp}^{3}$-hybridized form, due to the interaction between His 9 and the $p \mathrm{BoF}$ derived chromophore through a water bridge. We further postulated that the formation of the tetrahedral $\mathrm{sp}^{3}$-hybridized boronate chromophore might be the key for the observed unusual chemoselectivity of pnGFP. We assume that the oxidation of boronates mainly processes via three steps (Figure 7). In the first step, nucleophilic groups, such as peroxynitrite $\left(\mathrm{ONOO}^{-}\right)$, attack the boron atom. A subsequent cleavage of a weak $\mathrm{O}-\mathrm{O}$ bond induces the bond arrangement to insert an oxygen atom between the boron and the aryl carbon atom. In the last step, the boronic ester is hydrolyzed to form a phenol and boric acid.

For an $\mathrm{sp}^{2}$-hybridized boronic acid, nucleophilic attack by either $\mathrm{ONOO}^{-}$or $\mathrm{HOO}^{-}$is expected to be highly effective, due to the existence of an empty p-orbital of boron. Again, using DFT calculations without explicitly including the protein or the solvent, we found that the reaction between the $\mathrm{sp}^{2}$-hybridized phenylboronic acid and $\mathrm{ONOO}^{-}$or $\mathrm{HOO}^{-}$is thermodynamically very favorable (by -31.4 or $-59.3 \mathrm{kcal} / \mathrm{mol}$, respectively) and kinetically facile (essentially no activation energy). However, we found no direct combination between the neutral hydrogen peroxide $\left(\mathrm{H}_{2} \mathrm{O}_{2}\right)$ and the $\mathrm{sp}^{2}$-hybridized phenyl boronic acid. Once boron is converted from $\mathrm{sp}^{2}$ to $\mathrm{sp}^{3}$, nucleophilic attack on $\mathrm{sp}^{3}$-hybridized boron has to undergo an $\mathrm{S}_{\mathrm{N}}$ 2-like process. Indeed, our computed charge distribution showed that the $\mathrm{sp}^{2}$ hybridized boron in the boronic acid has a more positive charge $(+1.183)$ than the $\mathrm{sp}^{3}-$ hybridized boron of the imidazole-water-boronic acid complex $(+1.127$ charge). The formation of a new B-O bond between the $\mathrm{sp}^{3}$ phenyl boronate and $\mathrm{ONOO}^{-}$or $\mathrm{HOO}^{-}$is accompanied with the cleavage of the existing $\mathrm{B}-\mathrm{O}$ dative bond through a high-energy transition state along the reaction path. Thus, the reactivity with either $\mathrm{ONOO}^{-}$or $\mathrm{HOO}^{-}$is reduced, as evidenced by the higher activation energies $\left(15.5 \mathrm{kcal} / \mathrm{mol}\right.$ for $\mathrm{ONOO}^{-}$and 14.8 $\mathrm{kcal} / \mathrm{mol}$ for $\mathrm{HOO}^{-}$). Since the reaction is expected to proceed via the anionic or base form of hydrogen peroxide or peroxynitrite, the reaction between hydrogen peroxide and the $\mathrm{sp}^{3}$ hybridized boronate is expected to be much slower than the reaction between peroxynitrite and boronate. This is because the $\mathrm{pK}_{\mathrm{a}}$ of $\mathrm{H}_{2} \mathrm{O}_{2}\left(\mathrm{pK}_{\mathrm{a}}=11.6\right)$ is significantly higher than that of $\mathrm{ONOOH}\left(\mathrm{pK}_{\mathrm{a}}=6.8\right)$, and hence at neutral $\mathrm{pH}$, the portion of $\mathrm{HOO}^{-}$is much lower than the portion of $\mathrm{ONOO}^{-}$. This analysis is consistent with experimental observations that peroxynitrite is several orders of magnitude more reactive with aryl boronate than with hydrogen peroxide. ${ }^{57}$

\section{CONCLUSIONS}

One fundamental challenge and long sought-after problem in the field of ROS/RNS sensing lies in how to develop highly selective probes (i.e. probes that detect a particular ROS/RNS without interference from other species). We recently reported a highly selective fluorescent biosensor for peroxynitrite, which contains a boronic acid-derived chromophore in a cpGFP scaffold. To decipher the observed unusual chemoselectivity, we have utilized an array of experimental and computational methods to investigate the molecular mechanism. Sitedirected mutagenesis identified a critical His9 residue, which is in close proximity to the boronic acid-derived chromophore of pnGFP. A single His9Thr point mutation converted pnGFP to become highly reactive toward hydrogen peroxide. The X-ray crystal structure of cpGFP1.5-Y.Cro was determined at $2.75 \AA$ resolution, which suggests that His9 interacts 
with the chromophore of cpGFP1.5-Y.Cro via H-bond bridges through a bound water molecule. Our ${ }^{11} \mathrm{~B}$ NMR studies further confirmed a fully hydrated $\mathrm{sp}^{3}$-hybridized boronate anion in the chromophore of pnGFP. Computational analysis suggests that the N-B interaction through a water bridge is reasonable, and the resultant $\mathrm{B}-\mathrm{O}$ dative bond has a bonding energy of $-10.9 \mathrm{kcal} / \mathrm{mol}$.Our data also suggest that, only the anionic portions of hydrogen peroxide $\left(\mathrm{HOO}^{-}\right)$and peroxynitrite $\left(\mathrm{ONOO}^{-}\right)$can combine with either $\mathrm{sp}^{2}$ - or $\mathrm{sp}^{3}$ hybridized boronic acids; the reactions with $\mathrm{sp}^{3}$-hybridized boronic acids are thermodynamically and kinetically less favored than the reactions with $\mathrm{sp}^{2}$-hybridized boronic acids. Because the $\mathrm{pK}_{\mathrm{a}}$ of hydrogen peroxide $\left(\mathrm{H}_{2} \mathrm{O}_{2}\right)$ is several units higher than that of peroxynitrous acid $(\mathrm{ONOOH})$ and a negligible portion of hydrogen peroxide is anionic under physiological $\mathrm{pH}(\sim 7.4)$, pnGFP is essentially unreactive with low millimolar hydrogen peroxide.

In summary, our results collectively support that a His residue on the pnGFP protein scaffold interact with the boron atom in the chromophore through a bound water molecule and converts the boron atom to be $\mathrm{sp}^{3}$-hybridized, which further modulates the reactivity of pnGFP with ROS/RNS. Although other surrounding residues in the protein may also affect the chemoselectivity, e.g. by modulating the bond angle or length of the new B-O bond, the identified $\mathrm{sp}^{3}$-hybridized hydrated boronate itself is the determining factor for the unprecedented chemoselectivity of pnGFP. Our study unveils the first example of tunable boron chemistry in a folded nonnative protein, which will facilitate future development of highly selective aryl boronate-based sensors and inspire the tuning of chemical or biochemical reactions in protein scaffolds for a multitude of applications.

\section{Supplementary Material}

Refer to Web version on PubMed Central for supplementary material.

\section{ACKNOWLEDGMENT}

We acknowledge support from the National Science Foundation Grant (CHE-1351933), the National Institutes of Health (R03EB020211), the University of California-Riverside, and the UCR Academic Senate (Regents' Faculty Fellowship to H.A.). We thank Cambden Driggers at Oregon State University for help with crystallographic data collection and Tan Truong for critical reading of the manuscript. C321. $\Delta$ A.exp was a gift from George Church (Addgene plasmid \# 49018).

\section{REFERENCES}

(1). Lennox AJ, Lloyd Jones GC. Chem. Soc. Rev. 2014; 43:412. [PubMed: 24091429]

(2). Suzuki A. Angew. Chem. Int. Ed. Engl. 2011; 50:6722. [PubMed: 21618370]

(3). Smoum R, Rubinstein A, Dembitsky VM, Srebnik M. Chem. Rev. 2012; 112:4156. [PubMed: 22519511]

(4). Bachovchin DA, Cravatt BF. Nat. Rev. Drug Discov. 2012; 11:52. [PubMed: 22212679]

(5). Musto CJ, Suslick KS. Curr. Opin. Chem. Biol. 2010; 14:758. [PubMed: 20692199]

(6). Jin S, Cheng Y, Reid S, Li M, Wang B. Med. Res. Rev. 2010; 30:171. [PubMed: 19291708]

(7). James TD, Linnane P, Shinkai S. Chem. Commun. 1996:281.

(8). Martin AR, Vasseur JJ, Smietana M. Chem. Soc. Rev. 2013; 42:5684. [PubMed: 23538489]

(9). Lin VS, Dickinson BC, Chang CJ. Method Enzymol. 2013; 526:19. 
(10). Sikora A, Zielonka J, Lopez M, Joseph J, Kalyanaraman B. Free Radic. Biol. Med. 2009; 47:1401. [PubMed: 19686842]

(11). Trujillo M, Naviliat M, Alvarez MN, Peluffo G, Radi R. Analusis. 2000; 28:518.

(12). Jang B, Han S. Biochimie. 2006; 88:53. [PubMed: 16040185]

(13). Abello N, Kerstjens HA, Postma DS, Bischoff R. J. Proteome Res. 2009; 8:3222. [PubMed: 19415921]

(14). Takakura K, Beckman JS, MacMillan-Crow LA, Crow JP. Arch. Biochem. Biophys. 1999; 369:197. [PubMed: 10486138]

(15). Ohmori H, Kanayama N. Autoimmun. Rev. 2005; 4:224. [PubMed: 15893716]

(16). Mallozzi C, Di Stasi AM, Minetti M. FEBS Lett. 2001; 503:189. [PubMed: 11513880]

(17). Souza JM, Peluffo G, Radi R. Free Radic. Biol. Med. 2008; 45:357. [PubMed: 18460345]

(18). Szabo C, Ischiropoulos H, Radi R. Nat. Rev. Drug Discov. 2007; 6:662. [PubMed: 17667957]

(19). Allen RG, Lafuse WP, Powell ND, Webster Marketon JI, Stiner-Jones LM, Sheridan JF, Bailey MT. Infect. Immun. 2012; 80:3429. [PubMed: 22825446]

(20). Chen, Z.; Truong, TM.; Ai, HW. Development of Fluorescent Probes for the Detection of Peroxynitrite. In: Peteu, S.; Szunerits, S.; Bayachou, M., editors. Peroxynitrite Detection in Biological Media: Challenges and Advances. Royal Society of Chemistry; London, U.K.: 2016. p. 186

(21). Chen ZJ, Ren W, Wright QE, Ai HW. J. Am. Chem. Soc. 2013; 135:14940. [PubMed: 24059533]

(22). Lin KK, Wu SC, Hsu KM, Hung CH, Liaw WF, Wang YM. Org. Lett. 2013; 15:4242. [PubMed: 23924291]

(23). Peng T, Wong NK, Chen X, Chan YK, Ho DH, Sun Z, Hu JJ, Shen J, El-Nezami H, Yang D. J. Am. Chem. Soc. 2014; 136:11728. [PubMed: 25058034]

(24). Peng T, Yang D. Org. Lett. 2010; 12:4932. [PubMed: 20919741]

(25). Sun ZN, Wang HL, Liu FQ, Chen Y, Tam PKH, Yang D. Org. Lett. 2009; 11:1887. [PubMed: 19331349]

(26). Tian JW, Chen HC, Zhuo LH, Xie YX, Li N, Tang B. Chem-Eur J. 2011; 17:6626. [PubMed: 21590826]

(27). Ueno T, Urano Y, Kojima H, Nagano T. J. Am. Chem. Soc. 2006; 128:10640. [PubMed: 16910633]

(28). Xu KH, Chen HC, Tian JW, Ding BY, Xie YX, Qiang MM, Tang B. Chem. Commun. 2011; 47:9468.

(29). Yang D, Wang HL, Sun ZN, Chung NW, Shen JG. J. Am. Chem. Soc. 2006; 128:6004. [PubMed: 16669647]

(30). Yu F, Li P, Wang B, Han K. J. Am. Chem. Soc. 2013; 135:7674. [PubMed: 23621710]

(31). Yu F, Li P, Li G, Zhao G, Chu T, Han K. J. Am. Chem. Soc. 2011; 133:11030. [PubMed: 21702509]

(32). Zhang Q, Zhu Z, Zheng Y, Cheng J, Zhang N, Long YT, Zheng J, Qian X, Yang Y. J. Am. Chem. Soc. 2012; 134:18479. [PubMed: 22978649]

(33). Zielonka J, Sikora A, Joseph J, Kalyanaraman B. J. Biol. Chem. 2010; 285:14210. [PubMed: 20194496]

(34). Li X, Tao RR, Hong LJ, Cheng J, Jiang Q, Lu YM, Liao MH, Ye WF, Lu NN, Han F, Hu YZ, Hu YH. J. Am. Chem. Soc. 2015; 137:12296. [PubMed: 26352914]

(35). Gaupels F, Spiazzi-Vandelle E, Yang D, Delledonne M. Nitric Oxide-Biol. Ch. 2011; 25:222.

(36). Ieda N, Nakagawa H, Peng T, Yang D, Suzuki T, Miyata N. J. Am. Chem. Soc. 2012; 134:2563. [PubMed: 22239467]

(37). Kim J, Park J, Lee H, Choi Y, Kim Y. Chem. Commun. 2014; 50:9353.

(38). Zielonka J, Sikora A, Hardy M, Joseph J, Dranka BP, Kalyanaraman B. Chem. Res. Toxicol. 2012; 25:1793. [PubMed: 22731669]

(39). Lippert AR, De Bittner GCV, Chang CJ. Acc. Chem. Res. 2011; 44:793. [PubMed: 21834525]

(40). Miller EW, Albers AE, Pralle A, Isacoff EY, Chang CJ. J. Am. Chem. Soc. 2005; 127:16652. [PubMed: 16305254] 
(41). Karplus PA, Diederichs K. Science. 2012; 336:1030. [PubMed: 22628654]

(42). Otwinowski, Z.; Minor, W. Processing of X-ray Diffraction Data Collected in Oscillation Mode. In: Carter, CW., Jr.; Sweet, RM., editors. Methods Enzymol. Vol. 276. Academic Press; New York: 1997. p. 307

(43). CCP4. Acta Crystallogr. D Biol. Crystallogr. 1994; 50:760. [PubMed: 15299374]

(44). Adams PD, Afonine PV, Bunkoczi G, Chen VB, Davis IW, Echols N, Headd JJ, Hung LW, Kapral GJ, Grosse Kunstleve RW, McCoy AJ, Moriarty NW, Oeffner R, Read RJ, Richardson DC, Richardson JS, Terwilliger TC, Zwart PH. Acta Crystallogr. D Biol. Crystallogr. 2010; 66:213. [PubMed: 20124702]

(45). Kissinger CR, Gehlhaar DK, Fogel DB. Acta Crystallogr. D. 1999; 55:484. [PubMed: 10089360]

(46). Emsley P, Cowtan K. Acta Crystallogr. D. 2004; 60:2126. [PubMed: 15572765]

(47). Frisch, MJ.; Trucks, GW.; Schlegel, HB.; Scuseria, GE.; Robb, MA.; Cheeseman, JR.; Scalmani, G.; Barone, V.; Mennucci, B.; Petersson, GA.; Nakatsuji, H.; Caricato, M.; Li, X.; Hratchian, HP.; Izmaylov, AF.; Bloino, J.; Zheng, G.; Sonnenberg, JL.; Hada, M.; Ehara, M.; Toyota, K.; Fukuda, R.; Hasegawa, J.; Ishida, M.; Nakajima, T.; Honda, Y.; Kitao, O.; Nakai, H.; Vreven, T.; Montgomery, JA., Jr.; Peralta, JE.; Ogliaro, F.; Bearpark, MJ.; Heyd, J.; Brothers, EN.; Kudin, KN.; Staroverov, VN.; Kobayashi, R.; Normand, J.; Raghavachari, K.; Rendell, AP.; Burant, JC.; Iyengar, SS.; Tomasi, J.; Cossi, M.; Rega, N.; Millam, NJ.; Klene, M.; Knox, JE.; Cross, JB.; Bakken, V.; Adamo, C.; Jaramillo, J.; Gomperts, R.; Stratmann, RE.; Yazyev, O.; Austin, AJ.; Cammi, R.; Pomelli, C.; Ochterski, JW.; Martin, RL.; Morokuma, K.; Zakrzewski, VG.; Voth, GA.; Salvador, P.; Dannenberg, JJ.; Dapprich, S.; Daniels, AD.; Farkas, Ö.; Foresman, JB.; Ortiz, JV.; Cioslowski, J.; Fox, DJ. Gaussian 09, Revision D.01. Gaussian, Inc.; Wallingford, CT, USA: 2009.

(48). Zhao Y, Truhlar DG. Theor. Chem. Acc. 2007; 120:215.

(49). Glendening, ED.; Reed, AE.; Carpenter, JE.; Weinhold, F. NBO, version 3.1. University of Wisconsin; Madison: 1998.

(50). Lajoie MJ, Rovner AJ, Goodman DB, Aerni HR, Haimovich AD, Kuznetsov G, Mercer JA, Wang HH, Carr PA, Mosberg JA, Rohland N, Schultz PG, Jacobson JM, Rinehart J, Church GM, Isaacs FJ. Science. 2013; 342:357. [PubMed: 24136966]

(51). Wiskur SL, Lavigne JJ, Ait-Haddou H, Lynch V, Chiu YH, Canary JW, Anslyn EV. Org. Lett. 2001; 3:1311. [PubMed: 11348222]

(52). Islam TM, Yoshino K, Sasane A. Anal. Sci. 2003; 19:455. [PubMed: 12675359]

(53). Otsuka H, Uchimura E, Koshino H, Okano T, Kataoka K. J. Am. Chem. Soc. 2003; 125:3493. [PubMed: 12643711]

(54). Singhal, R. p.; Ramamurhy, B.; Govindraj, N.; Sarwar, Y. J. Chromatogr. A. 1991; 543:17.

(55). Zhu L, Shabbir SH, Gray M, Lynch VM, Sorey S, Anslyn EV. J. Am. Chem. Soc. 2006; 128:1222. [PubMed: 16433539]

(56). Hoang CT, Prokes I, Clarkson GJ, Rowland MJ, Tucker JHR, Shipman M, Walsh TR. Chem. Commun. 2013; 49:2509.

(57). Kalyanaraman B, Darley-Usmar V, Davies KJ, Dennery PA, Forman HJ, Grisham MB, Mann GE, Moore K, Roberts LJ 2nd, Ischiropoulos H. Free Radic. Biol. Med. 2012; 52:1. [PubMed: 22027063] 


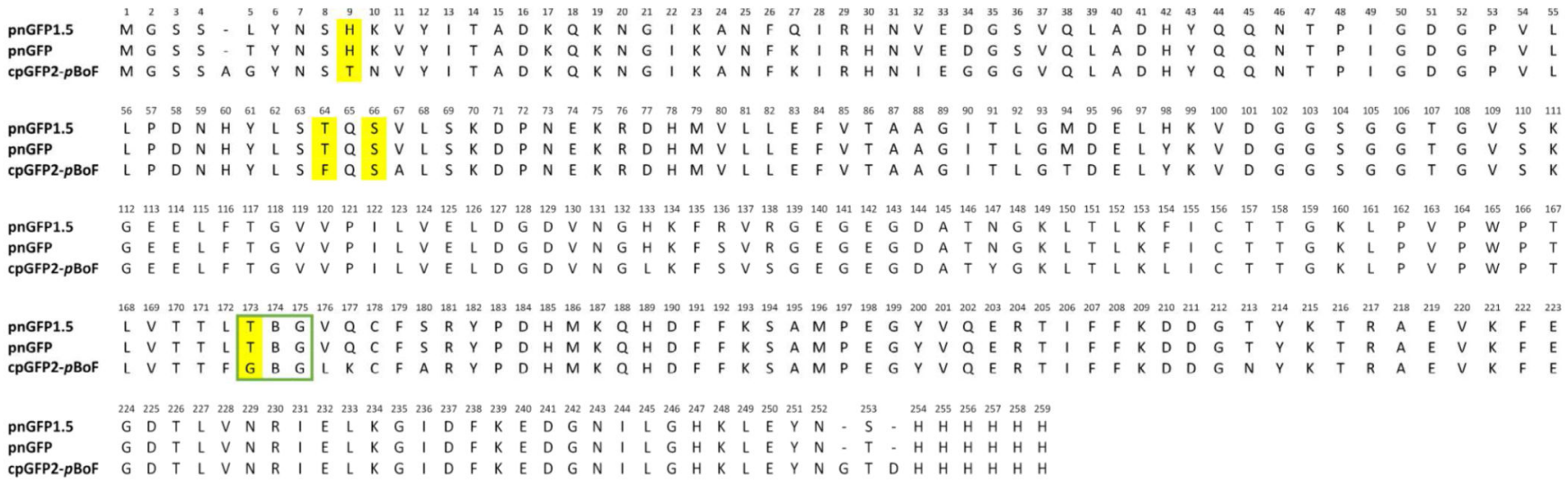

Figure 1. Sequence alignment of pnGFP, pnGFP1.5 and cpGFP2-pBoF

The chromophore-forming residues (including $\mathrm{B}$ representing $p \mathrm{BoF}$ at residue 174) are highlighted in a green box. Residues 9, 64, 66, and 173, which are either structurally close to residue 174 or the only variable chromophore-forming residue, are highlighted in yellow. 

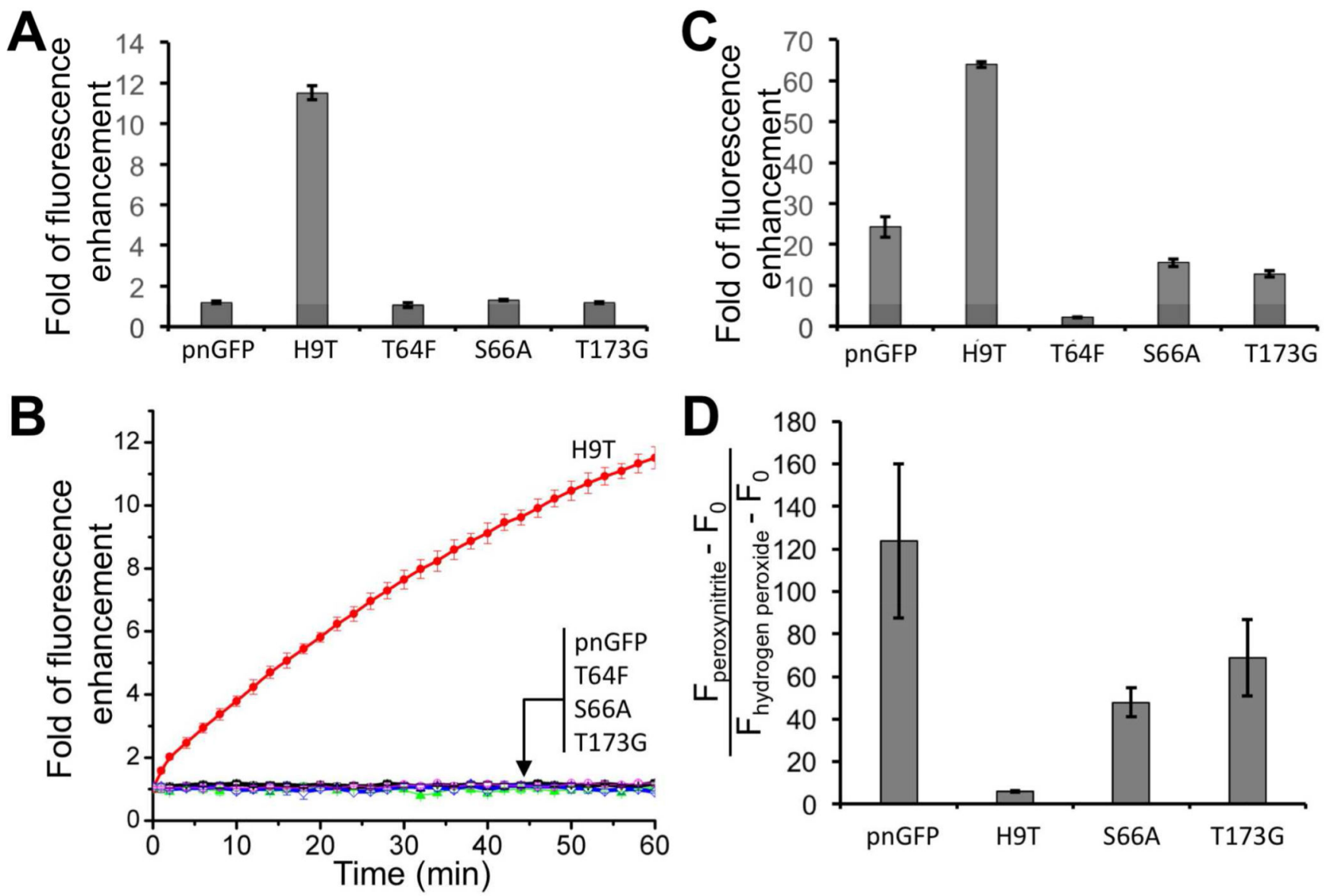

Figure 2. Fluorescence responses of pnGFP and pnGFP mutants to hydrogen peroxide and peroxynitrite

Panels $\mathrm{A}$ and $\mathrm{C}$ show the fold of fluorescence enhancement $\left(\mathrm{F} / \mathrm{F}_{0}\right)$ induced by hydrogen peroxide $(100 \mu \mathrm{M})$ or peroxynitrite $(100 \mu \mathrm{M})$, respectively. The measurement was performed $1 \mathrm{~h}$ post mixing. Panel B shows the kinetics of the reactions between hydrogen peroxide $(100 \mu \mathrm{M})$ and pnGFP (black) or pnGFP mutants, including pnGFP-H9T (red), pnGFP-T64F (green), pnGFP-S66A (blue), and pnGFP-T173G (magenta). The fluorescence intensities are normalized to intensity values at $0 \mathrm{~min}$. Panel D shows the ratios of peroxynitrite-induced fluorescence enhancement $\left(F\right.$ peroxynitrite $\left.-F_{0}\right)$ to hydrogen peroxide-induced fluorescence enhancement $\left(F_{\text {hydrogen peroxide }}-F_{0}\right)$. The ratio for pnGFP-T64F is not shown in Panel D, since pnGFP-T64F has very low fluorescence before and after treatment with either hydrogen peroxide or peroxynitrite. 

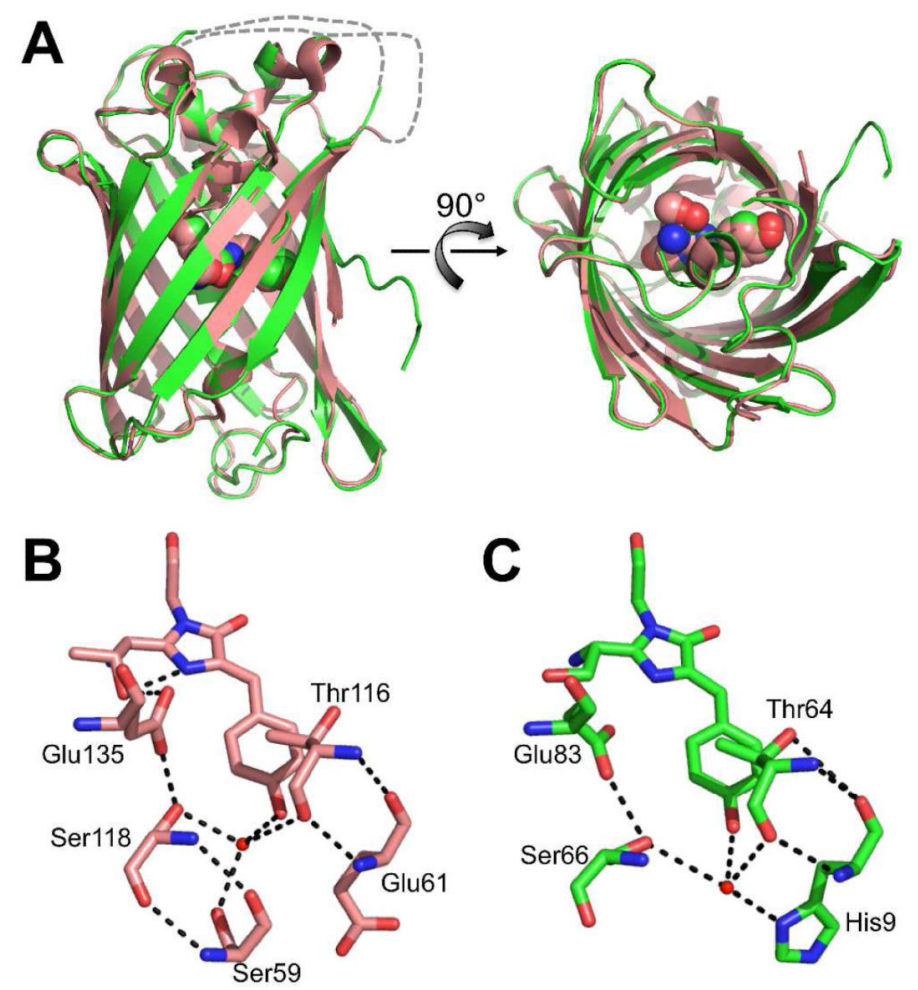

Figure 3. Structural comparison of pnGFP1.5-Y.Cro (green) and a circular-permutated EGFP (PDB 3EVP; red)

In panel $\mathrm{A}$ is an overlay of the overall $\mathrm{X}$-ray crystal structures shown in cartoon presentation, except for the chromophores in ball presentation. The gray dash lines represent floppy peptides unobserved by X-ray crystallography. Panel B shows the chromophore environment of the circular-permutated EGFP emphasizing H-bond partners and the water bridge adjacent to the chromophore. Panel $\mathrm{C}$ shows the chromophore environment of pnGFP1.5-Y.Cro. All H bonds are represented with black dashed lines. 


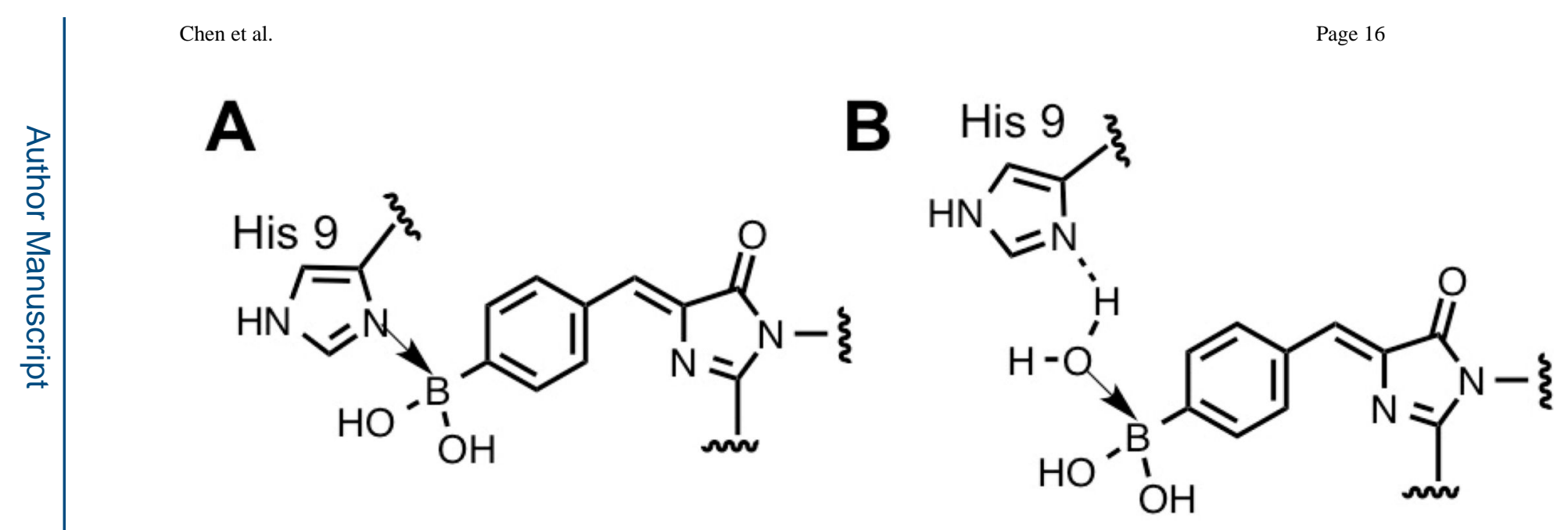

Figure 4.

Chemical structures showing potential interactions between His9 and the $p \mathrm{BoF}$-derived chromophore, including a direct N-B dative bond (A) or bonding through a polarized water bridge (B). 


\section{pnGFP1.5}
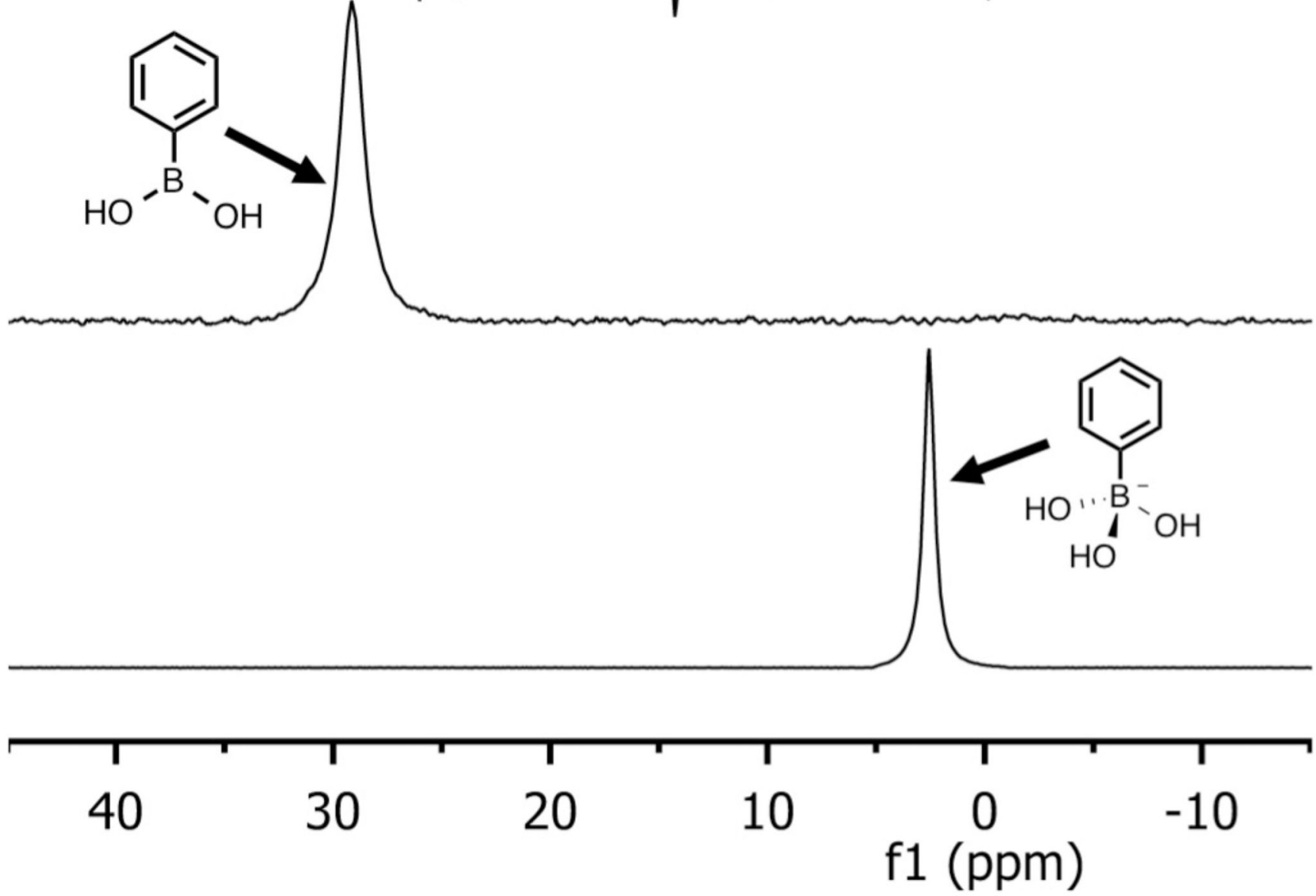

Figure 5.

${ }^{11}$ B NMR spectra for the indicated species (from top to bottom: pnGFP1.5, phenylboronic acid, and phenylboronic acid in $1 \mathrm{M} \mathrm{NaOH}$ ). 

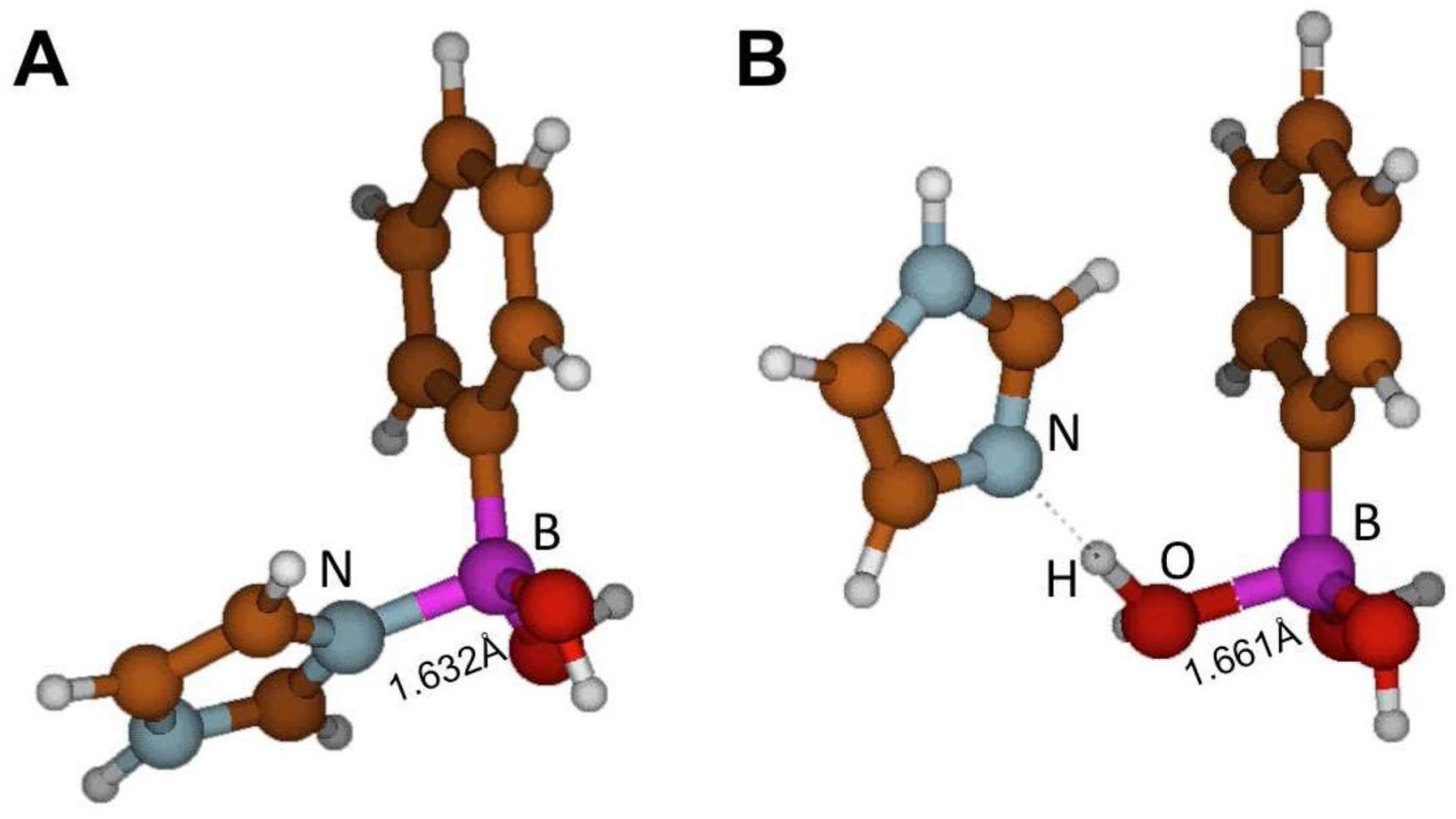

Figure 6.

Computational structures of the complexes between imidazole and phenylboronic acid, through either a B-N dative bond (A) or a polarized water-bridge (B). 
Step 1<smiles>Cc1ccc([As](O)(O)O)cc1</smiles>

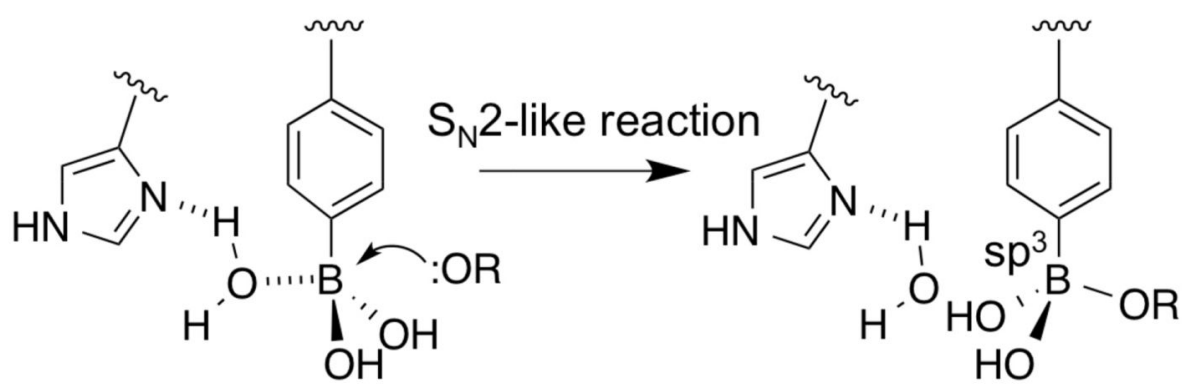

Step 2<smiles>[R][N+](=O)[O-]</smiles>

Step 3<smiles>Cc1ccc(OB(O)O)cc1</smiles>

Figure 7. A proposed reaction mechanism between $\mathrm{sp}^{2}$ - or $\mathrm{sp}^{3}$-hybridized boronates with peroxynitrite or hydrogen peroxide 